\title{
High Coercive Nd-Fe-B Sintered Magnets for High Temperature Application
}

\author{
D. H. Kim¹, A. S. Kim¹ , T. H. Lim², and T. S. Jang ${ }^{2 *}$ \\ ${ }^{1}$ Jahwa Electronics Co., Chungbuk 361-290, Korea \\ ${ }^{2}$ Department of Hybrid Engineering, Sunmoon University, Chungnam 336-708, Korea
}

(Received 3 November 2008, Received in final form 4 December 2008, Accepted 4 February 2009)

\begin{abstract}
Various sintered magnets containing $28 \sim 31 \mathrm{wt} \% \mathrm{Nd}$ and $0 \sim 7 \mathrm{wt} \%$ Dy were evaluated for coercivity and irreversible flux loss as a preliminary study to develop highly-coercive, high-temperature magnets that can be applied for driving motors in a hybrid vehicle. The sintered magnets were prepared in sequence of strip casting, HD treatment, jet milling, magnetic field pressing, sintering and post-annealing. Increasing Dy content and adjusting post-annealing temperature monotonically increased coercivity of magnets from about 14 kOe to 30 kOe. A magnet containing $28 \mathrm{wt} \% \mathrm{Nd}$ and $7 \mathrm{wt} \%$ Dy exhibits a $(\mathrm{BH})_{\max }+{ }_{i} H_{c}$ value of almost 64 . This is very close to what the automobile industry considers as the minimum value (65) for a hybrid vehicle system. Moreover, irreversible flux loss of the magnet was about $3 \%$ at $200{ }^{\circ} \mathrm{C}$, which is well less than the allowable limit $(5 \%)$ to a driving motor in hybrid vehicles.
\end{abstract}

Keywords : Nd-Fe-B, coercivity, thermal stability, irreversible flux loss

\section{Introduction}

Ever since Nd-Fe-B sintered magnets were commercially produced, they have mainly been used for the VCM of a hard disk drive, MRI, actuators and acoustic devices [1]. These types of application normally require the magnets to have a high remanence to increase the linear motion speed of an actuator like VCM or to enhance image resolution of a MRI. Magnets with coercivity of 14 to $16 \mathrm{kOe}$ is sufficient for these devices because they are usually operated below $80^{\circ} \mathrm{C}$ and exposed to a relatively low magnetic field.

Recently, Nd-Fe-B sintered magnets have been applied to a much broader field consisting of more dynamic devices such as BLDC motors, high power servo motors and generators [2] that require operation often in harsher conditions, i.e. higher temperature and higher external magnetic field. The magnets used in these applications therefore should be magnetically more stable with coercivities well over 21 kOe. For example, most urgent in the automobile industry is improvment of fuel efficiency and energy economy in order to overcome the oil crisis and other environmental problems. Many conventional internal combustion engines have either already been or

\footnotetext{
*Corresponding author: Tel: +82-41-530-2341
}

Fax: +82-41-544-1857, e-mail: tsjang@sunmoon.ac.kr are ready to be replaced by a hybrid system that utilizes high performance driving motors, creating so-called "hybrid vehicles". However, because the working temperature of a driving motor in a hybrid vehicle operates at high temperatures up to $200 \sim 220^{\circ} \mathrm{C}$, a high coercive permanent magnet is absolutely necessary to provide stable magnetic properties. In this study, the coercivity and irreversible flux loss of various Nd-Fe-B sintered magnets containing $28 \sim 31 \% \mathrm{Nd}$ and $0 \sim 7 \%$ Dy were investigated as an effort to develop such a magnet for hybrid vehicles.

\section{Experimental}

Initial alloys consisting of $\mathrm{RE}_{31 \sim 35} \mathrm{Fe}_{63-67} \mathrm{TM}_{1} \mathrm{~B}_{1}$ (in wt\%) were prepared by strip casting under $\mathrm{Ar}$ atmosphere. Nominal composition of the alloys is listed in Table 1. As shown in the table, RE stands for total amount of $\mathrm{Nd}$ and Dy while TM stands for total amount of minor elements such as $\mathrm{Al}, \mathrm{Cu}$, and $\mathrm{Co}$. The purity of the elements used in this study was $99.9 \mathrm{wt} \%$ for all. After hydrogenation and de-hydrogenation treatment, alloys crushed by a jet mill into a magnetic powder with an average particle size of $3.5 \mu \mathrm{m}$ were used to fill up a cylindrical mold with a tapping density of $2.0 \sim 2.2 \mathrm{~g} / \mathrm{cm}^{3}$. Magnetic alignment and pressing were done sequentially using TDP (transverse die pressing) process under a $2 \mathrm{~T}$ magnetic field. Finally, the compacts were sintered at $1060 \sim 1100^{\circ} \mathrm{C}$ for $4 \mathrm{~h}$ and 
Table 1. Composition of the Nd-Fe-B alloys.

\begin{tabular}{|c|c|c|c|c|c|}
\hline \multirow{2}{*}{$\begin{array}{c}\text { Elements } \\
\text { Alloys }\end{array}$} & \multicolumn{2}{|c|}{$\mathrm{RE}$} & \multirow{2}{*}{$\mathrm{TM}^{*}$} & \multirow{2}{*}{ B } & \multirow{2}{*}{$\mathrm{Fe}$} \\
\hline & $\mathrm{Nd}$ & Dy & & & \\
\hline M1 & 31 & 0 & 1 & 1 & 67 \\
\hline M2 & 30 & 2 & 1 & 1 & 66 \\
\hline M3 & 29 & 4 & 1 & 1 & 65 \\
\hline M4 & 28 & 6 & 1 & 1 & 64 \\
\hline M5 & 28 & 7 & 1 & 1 & 63 \\
\hline
\end{tabular}

*TM stands for total amount of minor elements such as $\mathrm{Al}, \mathrm{Cu}$, and $\mathrm{Co}$.

annealed at $450 \sim 550{ }^{\circ} \mathrm{C}$ for $2 \mathrm{~h}$, followed by pulse-magnetizing the sintered magnets at $5 \mathrm{~T}$. Magnetic properties of the magnets were measured with a BH loop tracer (Walker-AMH5020) with a maximum applied field of $3 \mathrm{~T}$ with the irreversible flux loss measured up to $200^{\circ} \mathrm{C}$ for 4 $\mathrm{h}$ using a flux-meter. Particle size analysis, phase analysis and microstructural investigation were performed with a particle size analyzer (TSI-aerosizer), a $\mathrm{Cu} \mathrm{K} \alpha$ X-ray diffractometer and a scanning electron microscope (Hitachi$3000 \mathrm{~N}$ ), respectively.

\section{Results and Discussion}

The remanence associated with Nd-Fe-B sintered magnets can now almost reach the magnetization saturation value due to the optimization of the degree of microstructure alignment [2]. Such an achievement is mainly accomplished by the technical improvement of two manufacturing methods: a strip casting process enabling the synthesis of an $\alpha$-Fe free ingot with homogenous phase distribution, and the development of various magnetic pressing methods such as isostatic press (CIP or RIP), wet press and pulse magnetic press [3-5]. Perfect alignment of magnetic powder with the direction of a magnetic field is possible by careful control of pressing conditions, thereby increasing remanence in proportion to the degree of alignment [6]. Compared to remanence, progress in improving coercivity of the Nd-Fe-B sintered magnets remains unsatisfactory with the coercivity of most commercially available Nd-Fe-B sintered magnets still only about $20 \sim 30 \%$ of the anisotropic magnetic field of $\mathrm{Nd}_{2} \mathrm{Fe}_{14} \mathrm{~B}\left(H_{a}=73\right.$ kOe) [7]. This means there is sufficient room to increase coercivity without sacrificing remanence.

\subsection{Effect of $B$ content}

It is well known Nd-Fe-B sintered magnets generally consist of three phases, i.e. hard magnetic $\mathrm{Nd}_{2} \mathrm{Fe}_{14} \mathrm{~B}$, nonmagnetic Nd-rich grain boundary phase and $\mathrm{Nd}_{1.1} \mathrm{Fe}_{4} \mathrm{~B}_{4}$. While the volume of the $\mathrm{Nd}_{2} \mathrm{Fe}_{14} \mathrm{~B}$ fraction directly influences the remanence value, homogeneous distribution of the Nd-rich phase plays an important role in improving

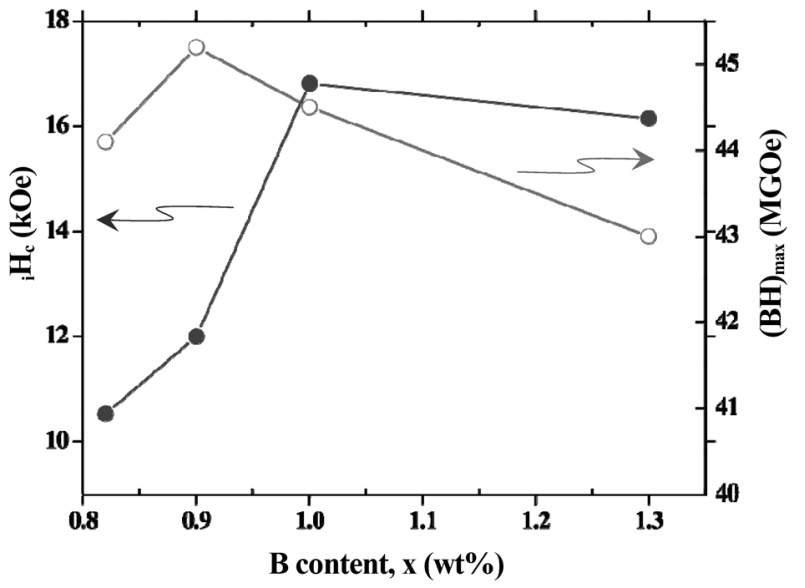

Fig. 1. Variation of ${ }_{i} H_{c}$ and $(B H)_{\max }$ as a function of $\mathrm{B}$ content for $\mathrm{Nd}_{30} \mathrm{Dy}_{2} \mathrm{Fe}_{67-\mathrm{X}} \mathrm{TM}_{1} \mathrm{~B}_{\mathrm{X}}$ sintered magnets.

coercivity. Since the $\mathrm{Nd}_{1.1} \mathrm{Fe}_{4} \mathrm{~B}_{4}$ phase does not benefit the magnetic properties of a magnet, the amount of $\mathrm{B}$ in the magnet should be controlled to suppress the formation of $\mathrm{Nd}_{1.1} \mathrm{Fe}_{4} \mathrm{~B}_{4}$ as much as possible.

Fig. 1 shows variations in the coercivity $\left(_{i} H_{c}\right)$ and energy product $\left((B H)_{\text {max }}\right)$ of $\mathrm{RE}_{32} \mathrm{Fe}_{66-\mathrm{x}} \mathrm{TM}_{1} \mathrm{~B}_{\mathrm{x}}$ sintered magnets when $x=0.8 \sim 1.3$. Both the coercivity and energy product responded sensitively according to the amount of $\mathrm{B}$ in the magnets, as shown in the figure. Coercivity decreased sharply when B content was insufficent (less than 1.0 $\mathrm{wt} \%$ ), forming some soft magnetic phases. However, when B content was more than $1.0 \mathrm{wt} \%$ the energy product decreased gradually in concert with the coercivity. Phase analysis revealed the magnet containing $1 \mathrm{wt} \% \mathrm{~B}$ $\left(\mathrm{RE}_{32} \mathrm{Fe}_{66} \mathrm{TM}_{1} \mathrm{~B}_{1}\right)$ consisted mostly of $\mathrm{Nd}_{2} \mathrm{Fe}_{14} \mathrm{~B}$ and Ndrich phases, whereas the magnet containing $1.3 \mathrm{wt} \% \mathrm{~B}$ $\left(\mathrm{RE}_{32} \mathrm{Fe}_{65.7} \mathrm{TM}_{1} \mathrm{~B}_{1.3}\right)$ included some $\mathrm{Nd}_{1.1} \mathrm{Fe}_{4} \mathrm{~B}_{4}$ phase. Therefore, the optimum amount of $\mathrm{B}$ in the magnets investigated was assumed to be $1 \mathrm{wt} \%$.

\subsection{Effect of rare-earth ( $\mathrm{Nd}$ and Dy) content}

Fig. 2 shows variation in the coercivity of $\mathrm{RE}_{31 \sim 35} \mathrm{Fe}_{63 \sim 67^{-}}$ $\mathrm{TM}_{1} \mathrm{~B}_{1}$ sintered magnets as a function of post-annealing temperature. Regardless of compositional changes, optimum coercivity values were obtained when the magnets were post-annealed at $500 \sim 525^{\circ} \mathrm{C}$, increasing slightly up to $525^{\circ} \mathrm{C}$ as the total amount of $\mathrm{Nd}$ and Dy increased from 31 to $35 \mathrm{wt} \%$. In all magnets, although no remarkable microstructural changes occurred before or after postannealing treatment, it was found the amount of $\mathrm{Fe}$ in the Nd-rich grain boundary phase, which was $14 \sim 18 \mathrm{wt} \%$ after sintering, was reduced to $5 \sim 7 \mathrm{wt} \%$ afterwards. This implies Fe atoms in the Nd-rich phase diffuse out to the matrix, decreasing the magnetism and thereby enhancing the magnetic isolation effect on hard magnetic grains. 


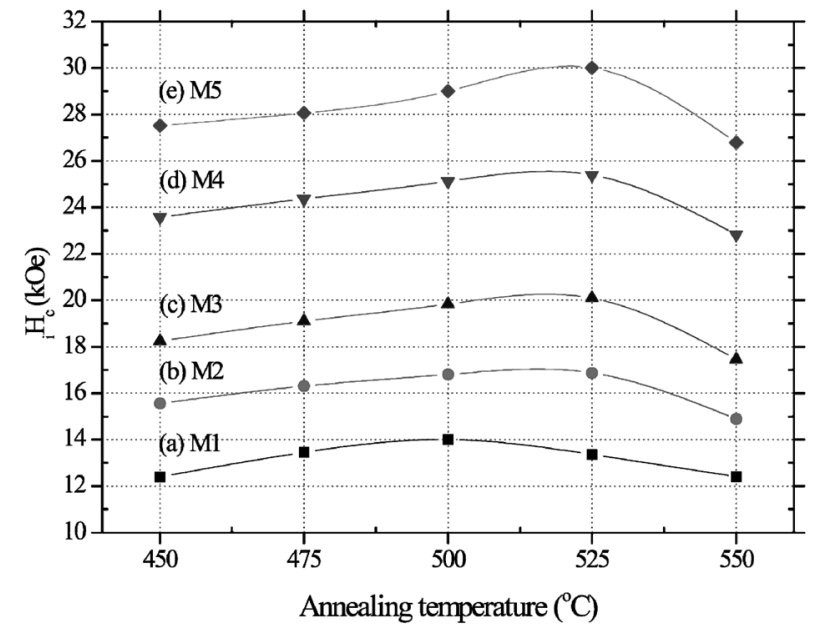

Fig. 2. Variation of ${ }_{i} H_{c}$ for the magnets M1 M5 listed in Table 1 , post-annealed at $450 \sim 550{ }^{\circ} \mathrm{C}$.

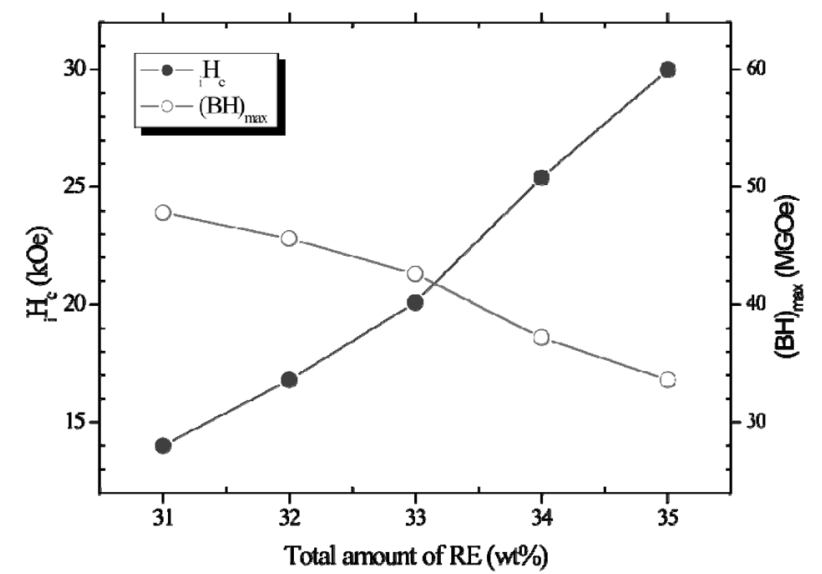

Fig. 3. Dependence of ${ }_{i} H_{c}$ and $(B H)_{\max }$ on total amount of rareearth (Nd and Dy) for the magnets M1 M5 listed in Table 1.

As shown in Fig. 3, as the total amount of rare earth increased, coercivity of the magnets post-annealed for $2 \mathrm{~h}$ at the optimum temperature also increased rapidly. In contrast, the energy product decreased gradually mostly due to the addition of Dy. The intrinsic coercivity and the energy product of a magnet containing $35 \mathrm{wt} \% \mathrm{RE}(28$ wt $\%$ Nd and $7 \mathrm{wt} \%$ Dy) were $30 \mathrm{kOe}$ and 33.8 MGOe, respectively. The value of ${ }_{i} H_{c}+(B H)_{\max }$ of this magnet is 63.8 , which is very close to the value the automobile industry considers as the minimum (65) for driving motors in a hybrid vehicle system.

Thermal stability of a magnet usually depends on the coercivity along with its temperature coefficient. It can be easily evaluated by measuring irreversible flux loss, i.e. calculating the difference between the magnetic flux measured at $20^{\circ} \mathrm{C}$ and at working temperature. Fig. 4 shows the irreversible flux loss of $\mathrm{RE}_{31 \sim 35} \mathrm{Fe}_{63 \sim 67} \mathrm{TM}_{1} \mathrm{~B}_{1}$ sintered

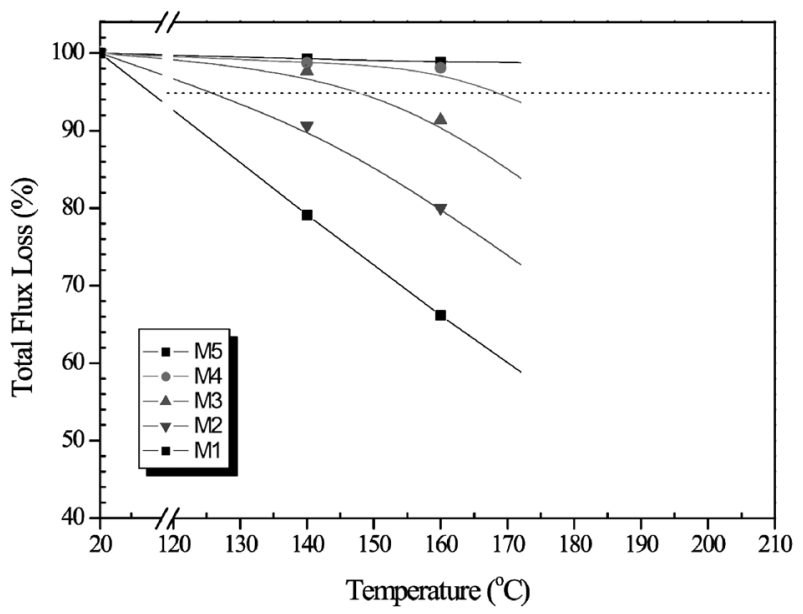

Fig. 4. Irreversible flux loss of the magnet M1 M5 listed in Table1, representing thermal stability of the magnets.

magnets which have coercivities in the range of 14 30 kOe. The magnets with higher coercivity exhibited less flux loss despite an increased working temperature. The irreversible flux loss of a magnet containing $35 \mathrm{wt} \% \mathrm{RE}$ was about $3 \%$ at $200^{\circ} \mathrm{C}$, well less than the allowable limit $(5 \%)$ in a hybrid vehicle system.

\section{Conclusion}

In order to develop highly-coercive, high-temperature magnets applicable to driving motors in a hybrid vehicle system, magnetic properties such as coercivity and irreversible flux loss were evaluated in Nd-Fe-B sintered magnets containing 28 31 wt $\% \mathrm{Nd}$ and $0 \sim 7 \mathrm{wt} \%$ Dy. Coercivity of the magnets increased monotonically from about 14 kOe to $30 \mathrm{kOe}$ by increasing Dy content and adjusting post-annealing temperature. The value of $(B H)_{\max }+{ }_{i} H_{c}$ of the magnet containing $28 \mathrm{wt} \% \mathrm{Nd}$ and $7 \mathrm{wt} \%$ Dy was 63.8 , which is close to the value the automobile industry considers as the minimum (65) for a hybrid vehicle system. Furthermore, irreversible flux loss of the magnet was about $3 \%$ at $200^{\circ} \mathrm{C}$, well less than the allowable limit $(5 \%)$ in a hybrid vehicle system.

\section{Acknowledgment}

This work was supported by "The R \& D program for core technology of materials" of the Ministry of Knowledge and Economy, Korea.

\section{References}

[1] Y. Luo, Proc. of the 2nd Int. symposium on magnetic industry conference, 1 (1999). 
[2] Y. Kaneko, Proc. of the 16th workshop on rare earth magnets and their applications, 83 (2000).

[3] F. Vial, J. Calvert, and M. Sagawa, Proc. of the 17th workshop on rare earth magnets and their applications, 372 (2002).

[4] W. Rodewald, B. Wall, M. Katter, K. Ustuner, and S. Steinmetz, Proc. of the 17th workshop on rare earth magnets and their applications, 25 (2002).
[5] H. Nagata and M. Sagawa, Proc. of the 17th workshop on rare earth magnets and their applications, 354 (2002).

[6] Y. Kaneko, K. Tokuhara, and N. Ishigaki, Jpn. J. Powder and Powder Metallurgy 41, 695 (1994).

[7] J. Liu and M. Walmer, Proc. of the 18th workshop on rare earth magnets and their applications, 630 (2004). 